\title{
Severity scores in COVID-19 pneumonia: a multicenter, retrospective, cohort study
}

\author{
Arturo Artero \\ University Hospital Doctor Peset \\ Manuel Madrazo ( $\square$ manel.madrazo@gmail.com ) \\ University Hospital Doctor Peset \\ Mar Fernández-Garcés \\ University Hospital Doctor Peset \\ Antonio Muñoz Miguez \\ Gregorio Marañon University Hospital \\ Andrés González García \\ Ramón y Cajal University Hospital \\ Anxela Crestelo Vieitez \\ Royo Villanova Hospital \\ Elena García Guijarro \\ Infanta Cristina University Hospital
}

Eva María Fonseca Aizpuru

Cabueñes Hospital

Miriam García Gómez

Urduliz Alfredo Espinosa Hospital

María Areses Manrique

Santa Marina Hospital

Carmen Martinez Cilleros

HLA Moncloa Hospital

María del Pilar Fidalgo Moreno

Henares Hospital

Jose Loureiro Amigo

Moisès Broggi Hospital

Ricardo Gil Sánchez

La Fe University Hospital

Elisa Rabadán Pejenaute

San Pedro Hospital

Lucy Abella Vázquez

Ntra Sra Candelaria University Hospital

Ruth Cañizares Navarro 
San Juan de Alicante University Hospital

\section{Marta Nataya Solís Marquínez}

San Agustin University Hospital

\section{Francisco Javier Carrasco Sánchez}

Juan Ramón Jiménez Hospital

Julio González Moraleja

Virgen de la Salud Hospital

\section{Lorena Montero Rivas}

Infanta Margarita Hospital

Joaquin Escobar Sevilla

Virgen de las Nieves University Hospital

María Dolores Martín Escalante

Costa del Sol Hospital

Ricardo Gómez-Huelgas

Málaga Regional University Hospital

Jose-Manuel Ramos-Rincon

Miguel Hernandez University of Elche

\section{Research Article}

Keywords: CURB-65, PSI, qSOFA, COVID-19, Community-acquired pneumonia

Posted Date: September 29th, 2020

DOI: https://doi.org/10.21203/rs.3.rs-83788/v1

License: (1) This work is licensed under a Creative Commons Attribution 4.0 International License. Read Full License

Version of Record: A version of this preprint was published at Journal of General Internal Medicine on February 11th, 2021. See the published version at https://doi.org/10.1007/s11606-021-06626-7. 
Title: Severity scores in COVID-19 pneumonia: a multicenter, retrospective, cohort study

Running title: Severity scores in COVID-19 pneumonia

Authors:

Arturo Artero Mora MD PhD (1)

Manuel Madrazo López MD (2)

Mar Fernández-Garcés MD PhD (2)

Antonio Muiño Miguez MD (3)

Andrés González García MD PhD ${ }^{(4)}$

Anxela Crestelo Vieitez MD ${ }^{(5)}$

Elena García Guijarro MD ${ }^{(6)}$

Eva María Fonseca Aizpuru MD (7)

Miriam García Gómez MD ${ }^{(8)}$

María Areses Manrique MD PhD ${ }^{(9)}$

Carmen Martinez Cilleros MD (10)

María del Pilar Fidalgo Moreno MD (11)

José Loureiro Amigo MD (12)

Ricardo Gil Sánchez MD (13)

Elisa Rabadán Pejenaute MD (14)

Lucy Abella Vázquez MD (15)

Ruth Cañizares Navarro MD (16) 
Marta Nataya Solís Marquínez MD ${ }^{(17)}$

Francisco Javier Carrasco Sánchez MD PhD (18)

Julio González Moraleja MD (19)

Lorena Montero Rivas MD ${ }^{(20)}$

Joaquín Escobar Sevilla MD (21)

María Dolores Martín Escalante MD ${ }^{(22)}$

Ricardo Gómez Huelgas MD PhD (23)

José Manuel Ramos Rincon MD PhD ${ }^{(24)}$; for the SEMI-COVID-19 Network**.

(1) Internal Medicine Department, Dr. Peset University Hospital, Universitat de València, Valencia, Spain

(2) Internal Medicine Department, Dr. Peset University Hospital, Valencia, Spain.

(3) Internal Medicine Department. Gregorio Marañon University Hospital, Madrid, Spain.

(4) Internal Medicine Department. Ramón y Cajal University Hospital, Madrid, Spain.

(5) Internal Medicine Department. Royo Villanova Hospital, Zaragoza, Spain.

(6) Internal Medicine Department. Infanta Cristina University Hospital, Parla (Madrid), Spain.

(7) Internal Medicine Department. Cabueñes Hospital, Gijón (Asturias), Spain.

(8) Internal Medicine Department. Urduliz Alfredo Espinosa Hospital, Urdúliz (Vizcaya), Spain.

(9) Internal Medicine Department. Santa Marina Hospital, Bilbao, Spain.

(10) Internal Medicine Department. HLA Moncloa Hospital, Madrid, Spain.

(11) Internal Medicine Department. Henares Hospital, Coslada (Madrid), Spain. 
(12) Internal Medicine Department. Moisès Broggi Hospital, Sant Joan Despí (Barcelona), Spain.

(13) Internal Medicine Department. La Fe University Hospital, Valencia, Spain.

(14) Internal Medicine Department. San Pedro Hospital, Logroño (La Rioja), Spain.

(15) Internal Medicine Department. Ntra Sra Candelaria University Hospital, Santa Cruz de Tenerife, Spain.

(16) Internal Medicine Department. San Juan de Alicante University Hospital, San Juan de Alicante (Alicante), Spain.

(17) Internal Medicine Department. San Agustin University Hospital, Avilés (Asturias), Spain.

(18) Internal Medicine Department. Juan Ramón Jiménez Hospital, Huelva, Spain.

(19) Internal Medicine Department. Virgen de la Salud Hospital, Toledo, Spain.

(20) Internal Medicine Department. Infanta Margarita Hospital, Cabra (Córdoba), Spain.

(21) Internal Medicine Department. Virgen de las Nieves University Hospital, Granada, Spain.

(22) Internal Medicine Department. Costa del Sol Hospital, Marbella (Málaga), Spain.

(23) Internal Medicine Department. Málaga Regional University Hospital, Málaga, Spain

(24) Department of Clinical Medicine, Miguel Hernandez University of Elche, Alicante, Spain 
Corresponding author:

Manuel Madrazo López

- mail: manel.madrazo@gmail.com

- phone number: +34 634222761

- Address: Avda Gaspar Aguilar, n 90, postal code 46017, Valencia, Spain

Number of references: 36 references

Number of tables: 3 tables

Number of figures: 2 figures

Number of appendices: 0

Word length: 2148 words

Keywords: CURB-65; PSI; qSOFA; COVID-19; Community-acquired pneumonia

Funding:

No funding was received for this study.

Conflict of interest:

The authors have no conflicts of interest. 
Abstract

Background: Identification of patients on admission to hospital with Coronavirus infectious disease 2019 (COVID-19) pneumonia who can develop poor outcomes have not yet ben comprehensively assessed.

Objective: To compare severity scores used for community acquired pneumonia to identify high-risk patients with COVID-19 pneumonia.

Design: PSI, CURB-65, qSOFA and MuLBSTA, a new score for viral pneumonia, were calculated on admission to hospital to identify high-risk patients for in-hospital mortality. Area under receiver operating characteristics curve (AUROC), sensitivity and specificity for each score were determined and AUROC were compared among them.

Participants: Patients with COVID-19 pneumonia included in the SEMI-COVID19 Network.

Key results: We examined 10,238 patients with COVID-19. Mean age of patients was 66.6 years and $57.9 \%$ were males. The most common comorbidities were: hypertension $(49.2 \%)$, diabetes (18.8\%) and chronic obstructive pulmonary disease (12.8\%). Acute respiratory distress syndrome $(34.7 \%)$ and acute kidney injury (13.9\%) were the most common complications. In-hospital mortality was 20.9\%. PSI and CURB-65 showed the highest AUROC (0.835 and0.825, respectively). qSOFA and MuLBSTA had a lower AUROC (0.728 and 0.715 , respectively). qSOFA was the most specific score (specificity $95.7 \%$ ) albeit its sensitivity was only $26.2 \%$. PSI had the highest sensitivity (84.1\%) and a specificity of $72.2 \%$.

Conclusions: PSI and CURB-65, specific severity scores for pneumonia, were the best scores for COVID-19 pneumonia and were better than qSOFA and MuLBSTA. Additionally, qSOFA, the simplest score to perform, was the most specific albeit the least sensitive. 
Text

\section{Background}

At the end of 2019, a novel coronavirus was identified as the cause of an outbreak of pneumonia cases in Wuhan, Hubei Province, China. This virus, now known as severe acute respiratory syndrome coronavirus 2 (SARS-CoV-2), rapidly spread around the world, causing a pandemic that has affected more than 22.5 million people as of 21 th august, $2020.1,2,3$ The disease that it produces is called coronavirus disease 2019 (COVID-19) and is characterized by a wide spectrum of infectious symptoms that range from mild to severe, with acute respiratory distress syndrome (ARDS) as its primary complication. ${ }^{4,5,6}$ Hospitalization is required in $6 \%$ to $20 \%$ of patients. 7,8 Mortality among hospitalized patients is high, ranging from $11 \%$ to $28 \%{ }^{4,5}$ Therefore, early and simple identification upon admission to hospital of patients who may have poor outcomes would be of considerable value and may help lead to prompt treatment and an optimized use of resources.

Several prognostic scores have been developed to identify elevated risk of death in patients with community-acquired pneumonia (CAP). Two of them, the Pneumonia Severity Index (PSI) and the Confusion, Urea, Respiratory rate, Blood pressure, 65 years of age and older (CURB-65) score, are well-validated scores for supporting pneumonia prognoses. ${ }^{9,} 10$ The multilobar infiltration, hypo-lymphocytosis, bacterial coinfection, smoking history, hypertension, and age (MuLBSTA) score, which is based on six parameters routinely measured in hospitals, is a new prognostic tool for patients hospitalized with viral pneumonia $^{11}$ and has been suggested as a severity score for patients with COVID-19. ${ }^{5}$ The quick sequential organ failure assessment scale (qSOFA), 
based on the sepsis- 3 definition, ${ }^{12}$ has proven to be a useful tool in the emergency department, ${ }^{13,} 14$ non-intensive-care-unit (ICU) wards, ${ }^{15,16,17}$ and even at home ${ }^{18,19}$ for establishing a prognosis in patients with documented or suspected infection with different foci. Recent works indicate that qSOFA is also a useful tool for identifying patients with poor prognoses in viral infections such as influenza.20, 21, 22 In addition, qSOFA has shown good performance in predicting prognosis in pneumonia, both in the emergency department $23,24,25$, 26, 27 and in wards. ${ }^{28}$ The advantage of the qSOFA score is that the variables are clinical and thus laboratory tests are not required. ${ }^{12}$

Objective

In this study, we aim to ascertain the applicability and prognostic prediction value of the PSI, CURB-65, MuLBSTA, and qSOFA severity scores in COVID19 patients with pneumonia admitted to hospital.

Design

Study design and participants

This work is a multicenter retrospective cohort study of patients with SARSCoV2 infection, aged $\geq 18$ years, and with CAP who were hospitalized between March $1^{\text {st }}$ and May 28 2020 in Spain and included in the aforementioned SEMI-COVID-19 Registry. ${ }^{29}$ The registry is an initiative of the Spanish Society of Internal Medicine (SEMI, for its initials in Spanish), its characteristics have been described elsewhere. ${ }^{29}$ Data are collected retrospectively and include 
epidemiological and clinical characteristics, such as comorbidities, symptoms, physical examination findings, laboratory and diagnostic imaging test results, and clinical outcomes.

Definition of variables

COVID-19 pneumonia was defined as compatible symptoms (cough, dyspnea, need for respiratory support, fever, or crackling or rales on auscultation), pulmonary infiltrates or consolidation detected by a chest X-ray or computerized tomography (CT) scan, and a positive result on either a polymerase chain reaction test of a nasopharyngeal sample or a serology test for COVID-19 antibodies.

We defined PSI, CURB-65, MuLBSTA, and qSOFA as originally described. ${ }^{9,}$ 10, 11,12 The PSI is a scale with 19 variables with different point values. ${ }^{9} \mathrm{~A}$ cut-off of 91 points (Risk Class IV-V) was considered positive for a poor prognosis. ${ }^{24,} 25$, 26, 27, 28 We considered CURB-65 to be predictive of poor prognosis when three of the five variables (confusion, BUN $>7 \mathrm{mmol} / \mathrm{L}$, respiratory rate $\geq 30 \mathrm{bpm}$, systolic blood pressure $<90 \mathrm{mmHg}$ or diastolic blood pressure $\leq 60 \mathrm{mmHg}$, and age $\geq 65$ years) were positive. ${ }^{21}, 22,23,24$ The MuLBSTA score is a newly designed score for viral pneumonia ${ }^{11}$ that considers the following variables: multilobar infiltrates (5 points), lymphocytes $\leq 0.8 \times 10 \mathrm{e} / \mathrm{ml}$ ( 4 points), bacterial infection (4 points), active smoker (3 points), prior smoker (2 points), hypertension ( 2 points), and age $\geq 60$ years ( 2 points), with a cut-off point of 12 points or more is related with poor prognosis, as defined in the original study. ${ }^{11}$ qSOFA was considered positive when two of the three variables (altered mental 
status, respiratory rate $\geq 22 \mathrm{brpm}$, and/or systolic blood pressure $<100 \mathrm{mmHg}$ ) were met, according to the Sepsis-3 definition. ${ }^{12}$

\section{Outcome measures}

The primary outcome measure was all-cause in-hospital mortality.

Statistical analysis

After a preliminary descriptive analysis of the data (SD, means, and percentages), we compared the differences between categorical variables using the chi-square test and continuous variables using Student's t-test or analysis of variance. Statistical data from ROC curves (area under the curve (AUROC), sensitivity, and specificity) of the scores were calculated. The SPSS statistical package version 22.0 (SPSS, Chicago, IL) was used for the statistical study and the Epidat version 3.1 program was used for comparing the AUROCs of the different scales. $\mathrm{P}$ values $<0.05$ were considered statistically significant.

\section{Ethical aspects}

Scientific and ethical permission to conduct this study was obtained from the Provincial Research Ethics Committee of Málaga (Spain). Informed consent was obtained from patients for the purpose of publication. Personal data were processed in strict compliance with Spanish Law 14/2007, of July 3, on Biomedical Research; Regulation (EU) 2016/679 of the European Parliament and of the Council of 27 April 2016 on the protection of natural persons with regard to the processing of personal data and on the free movement of such data (General Data Protection Regulation); and Spanish Organic Law 3/2018, of December 5, on Personal Data Protection and the Guarantee of Digital Rights. 
Key results

A total of 10238 patients were included in this study. The patient inclusion flowchart can be seen in figure 1. Epidemiological and clinical data are found in table 1 . The mean age was $66 \cdot 6 \pm 16 \cdot 2$ years and $57.9 \%$ of patients were male. A total of 5830 (56.9\%) patients had an age-adjusted Charlson Comorbidity Index of 3 or more points. The most frequent comorbidities were hypertension $(49 \cdot 2 \%)$, diabetes (18.8\%), and COPD (12.2\%). ARDS and acute kidney injury were the most common complications (34.7\% and $13.9 \%$, respectively).

In-hospital mortality was 20.9\% (2135 cases). A total of 907 (8.9\%) patients were admitted to ICU. The mean length of hospital stay was $11 \cdot 2 \pm 9 \cdot 2$ days. As expected, the patients who died were older and had more comorbidities and complications. Prognostic scores were more frequently positive in deceased patients, as can be seen in table 1. Patients who died also had a longer mean hospital stay ( 9.7 vs 11.6 days, $p<0.001)$ and were more frequently admitted to the ICU $(17 \cdot 6 \%$ vs $6 \cdot 6 \%, p<0 \cdot 001)$.

The PSI and CURB-65 scores showed no statistical differences upon comparison (AUROC 0.835 vs $0.825, \mathrm{p}=0.112$ ) and were higher than the qSOFA and MuLBSTA scores (AUROC 0.728 and 0.715 , respectively, $p<0.001$ for both compared to PSI and CURB-65). These findings can be seen in table 2 and figure 2. The qSOFA score showed no differences compared to the MuLBSTA score (AUROC 0.728 vs $0.715, p=0.102$ ) and was the most specific score $(95 \cdot 72 \%)$, as can be seen in table 3 , but it had a lower sensitivity. The PSI risk class IV-V had the highest sensitivity (84.12\%) but a lower specificity 
than the qSOFA and MuLBSTA scores $(72.25 \%$ vs $95.72 \%$ and $91.23 \%, p$ $<0.001$ for both scores).

\section{Discussion}

To our knowledge, this is the largest study evaluating prognostic scores in patients with COVID-19 pneumonia. The in-hospital mortality observed in this multicenter study in Spain was high (20.9\%), which could be due to the fact that the mean age of patients was 66.6 years and there was a high frequency of comorbidities. The information obtained at admission allowed us to compare severity scores for identifying patients at high risk of in-hospital death. The PSI and CURB-65 had the best prognostic accuracy, with an AUROC of 0.835 and 0.825 , respectively.

The PSI was initially designed to help practitioners identify which low-risk patients with CAP could be safely treated in an outpatient setting, ${ }^{9}$ although it has subsequently been used to assess post-discharge mortality for those treated as inpatients. The capability of PSI to predict hospital mortality in our study was similar or even slightly better than that of other previous studies in CAP, in which PSI presented an AUROC of 0.778 to predict 30 -day mortality or transfer to $\mathrm{UCl}{ }^{28}$ and 0.812 to predict 30 -day mortality. ${ }^{30}$ Our findings provide evidence that the PSI is quite a good score for assessing the risk of in-hospital mortality for patients admitted with COVID-19 pneumonia.

CURB-65 was developed to stratify hospitalized patients with CAP into mortality risk groups, with a primary outcome measure of 30-day mortality. ${ }^{10}$ It has shown

a diagnostic performance for mortality similar to the PSI in CAP. ${ }^{24}$ The 
diagnostic performance for mortality found in our study was comparable to that found in another study on COVID-19 patients (AUROC 0.85) whose primary outcome measure was intensive respiratory or vasopressor support. ${ }^{31}$ In addition, our results were slightly better in terms of predicting mortality than those observed in another study on patients with influenza pneumonia (AUROC $0 \cdot 788) .^{32}$

MuLBSTA is a recently described severity score for 90 -day mortality in patients with viral pneumonia. ${ }^{11}$ It has been shown to perform better than CURB-65 in viral pneumonia, mainly caused by influenza virus; human rhinovirus; and respiratory syncytial virus. ${ }^{11}$ Chen et al. suggested using MuLBSTA as a severity score for COVID-19 in their description of 99 patients in Wuhan, China ${ }^{5}$ because the patients who died had a high percentage of variables included in this score. In our results, the AUROC of MuLBSTA for mortality $(0.715)$ showed lower sensitivity compared to the other scores as well as when compared to the original work $(0.715$ vs $0.773, p<0.001)$. Further studies are needed in order to prove the suitability of the MuLBSTA score.

In our study, qSOFA showed a lower sensitivity than the PSI and CURB-65 scores (AUROC 0.728 vs 0.835 and $0.825, p<0.001$ for both scores). These results were in line with the results found by Su et al. ${ }^{31}$ in their study on 116 patients with COVID-19 in China, which showed the superiority of CRB-65 vs qSOFA for prediction of intensive respiratory or vasopressor support (AUROC 0.81 vs $0.70, p 0.02$ ). Other studies have also shown that the accuracy of qSOFA in patients with COVID-19 was limited, ${ }^{33,}{ }^{34}$ although these studies included a small number of patients. However, qSOFA has been related to 
mortality in COVID-19 in another study with 191 patients (OR 12 (Cl 95\% 5.06$28 \cdot 43) \cdot{ }^{4}$

In our work, the PSI and CURB-65 showed sensitivity and specificity values similar to those found in other studies on CAP. ${ }^{23,28,30}$ However, qSOFA sensitivity was lower than the other scores and lower for CAP (53\% to $70 \cdot 1 \%) .{ }^{23,} 26$ qSOFA had a higher specificity than the other scores in our study (95.72\% vs $72 \cdot 25 \%, 90 \cdot 68 \%$, and $91.23 \%$ for PSI, CURB-65, and MuLBSTA, respectively). These results for qSOFA are consistent with the findings of Su et al., ${ }^{31}$ who observed a similar specificity for qSOFA and CURB-65 (98.9\% and $96 \cdot 7 \%$, respectively). Despite its lower sensitivity, qSOFA has the benefit of not requiring laboratory test results.

In the study by Su et al., ${ }^{31}$ the CRB score was also analyzed, which also has the benefit of not requiring laboratory results. In that study, no difference was found between CRB and qSOFA. ${ }^{31}$ These two scores had a lower accuracy than CRB-65 and CURB-65, suggesting that age is an important risk factor for mortality. Indeed, age has been shown to be an independent risk factor for mortality in patients with COVID-19.35, 36

This study has several limitations. First, due to its retrospective design, some possible confounding variables were not recorded and thus we could not calculate prognostic scores in $3.4 \%$ to $9.5 \%$ of cases. Second, we focused only on hospitalized patients and as such, we cannot be certain that our findings can be extrapolated to outpatients. Third, by excluding patients still hospitalized as of May 29, 2020, the case fatality rate in our study does reflect the true mortality rate of COVID-19. Fourth, this study was conducted in multiple centers in Spain 
and its results may not be applicable to other settings with different populations or healthcare systems.

Lastly, it is important to note that although these scores could help physicians identify patients with COVID-19 pneumonia at admission to hospital who have different risk levels for death, there are other risk factors specific to COVID-19 that should be considered, such as lymphopenia or D-dimer, ${ }^{4}$ which are not analyzed in these scores.

Conclusions

The PSI and CURB-65, two severity scores specific to pneumonia, were the best scores for predicting all-cause in-hospital death for patients with COVID-19 pneumonia. They performed better than the qSOFA and MuLBSTA severity scores. qSOFA, the simplest score to calculate, was the most specific, albeit the least sensitive.

Acknowledments:

We want to thank the contribution of the SEMI-COVID-19 Network for data retrieval.

References 
1. Lu H, Stratton C, Tang Y. Outbreak of pneumonia of unknown etiology in Wuhan, China: The mystery and the miracle. Journal of Medical Virology. 2020;92(4):401-2.

2. Lin L, Lu L, Cao W, Li T. Hypothesis for potential pathogenesis of SARSCoV-2 infection-a review of immune changes in patients with viral pneumonia. Emerg Microbes Infect. 2020;9(1):727-32.

3. Coronavirus disease (COVID-19) Situation Report. https://covid19.who.int/: World Health Organization; 2020, consulted on 21th august 2020.

4. Zhou F, Yu T, Du R, et al. Clinical course and risk factors for mortality of adult inpatients with COVID-19 in Wuhan, China: a retrospective cohort study. The Lancet. 2020;395(10229):1054-62.

5. Chen N, Zhou M, Dong X, et al. Epidemiological and clinical characteristics of 99 cases of 2019 novel coronavirus pneumonia in Wuhan, China: a descriptive study. The Lancet. 2020;395(10223):507-13.

6. Ruan Q, Yang K, Wang W, Jiang L, Song J. Clinical predictors of mortality due to COVID-19 based on an analysis of data of 150 patients from Wuhan, China. Intensive Care Med. 2020;46(5):846-8.

7. Rosenberg ES, Dufort EM, Blog DS, et al. COVID-19 Testing, Epidemic Features, Hospital Outcomes, and Household Prevalence, New York StateMarch 2020. Clin Infect Dis. 2020.

8. Wu Z, McGoogan J. Characteristics of and important lessons from the Coronavirus Disease 2019 (COVID-19) outbreak in China. Summary of a Report of 72314 cases from the Chinese Center for Disease Control and Prevention. JAMA. 2020;323(13):1239-42. 
9. Fine M, Hough L, Medsger A, et al. The hospital admission decision for patients with community acquired pneumonia. Arch Intern Med 1997;157:36-44. 10. Lim W, van der Eerden M, Laing R, et al. Defining community acquired pneumonia severity on presentation to hospital: an international derivation and validation study. Thorax. 2003;58:377-82.

11. Guo L, Wei D, Zhang X, et al. Clinical Features Predicting Mortality Risk in Patients With Viral Pneumonia: The MuLBSTA Score. Front Microbiol. 2019;10:2752.

12. Seymour CW, Liu VX, Iwashyna TJ, et al. Assessment of Clinical Criteria for Sepsis: For the Third International Consensus Definitions for Sepsis and Septic Shock (Sepsis-3). JAMA. 2016;315(8):762-74.

13. Freund $\mathrm{Y}$, Lemachatti N, Krastinova E, et al. Prognostic Accuracy of Sepsis-3 Criteria for In-Hospital Mortality Among Patients With Suspected Infection Presenting to the Emergency Department. JAMA. 2017;317(3):301-8.

14. April MD, Aguirre J, Tannenbaum LI, et al. Sepsis Clinical Criteria in Emergency Department Patients Admitted to an Intensive Care Unit: An External Validation Study of Quick Sequential Organ Failure Assessment. J Emerg Med. 2017;52(5):622-31.

15. Ramos-Rincón J, Fernández-Gil A, Merino E, et al. The quick Sepsisrelated Organ Failure Assessment (qSOFA) is a good predictor of in-hospital mortality in very elderly patients with bloodstream infections. A retrospective observational study. Sci Rep. 2019;9(1):15075.

16. LeGuen $\mathrm{M}$, Ballueer $\mathrm{Y}$, McKay $\mathrm{R}$, et al. Frequency and significance of qSOFA criteria during adult rapid response team reviews: A prospective cohort study. Resuscitation. 2018;122:13-8. 
17. Siddiqui S, Chua M, Kumaresh V, Choo R. A comparison of pre ICU admission SIRS, EWS and q SOFA scores for predicting mortality and length of stay in ICU. J Crit Care. 2017;41:191-3.

18. Vaittinada Ayar P, Delay M, Avondo A, et al. Prognostic value of prehospital quick sequential organ failure assessment score among patients with suspected infection. Eur J Emerg Med. 2019;26(5):329-33.

19. Koyama S, Yamaguchi Y, Gibo K, Nakayama I, Ueda S. Use of prehospital qSOFA in predicting in-hospital mortality in patients with suspected infection: A retrospective cohort study. PLoS One. 2019;14(5):e0216560.

20. Yeh CC, Chen YA, Hsu CC, et al. Quick-SOFA score>/2 predicts prolonged hospital stay in geriatric patients with influenza infection. Am J Emerg Med. 2020;38(4):780-4.

21. Papadimitriou-Olivgeris M, Gkikopoulos N, Wust M, et al. Predictors of mortality of influenza virus infections in a Swiss Hospital during four influenza seasons: Role of quick sequential organ failure assessment. Eur J Intern Med. 2020;74:86-91.

22. Chang SH, Yeh CC, Chen YA, et al. Quick-SOFA score to predict mortality among geriatric patients with influenza in the emergency department. Medicine (Baltimore). 2019;98(23):e15966.

23. George N, Elie-Turenne MC, Seethala RR, et al. External Validation of the qSOFA Score in Emergency Department Patients With Pneumonia. J Emerg Med. 2019;57(6):755-64.

24. Ranzani O, Prina E, Menéndez R, et al. New Sepsis Definition (Sepsis-3) and Community-Acquired Pneumonia Mortality: a validation and clinical decision-making stuy. Am J Respir Crit Care Med 2017;196(10):1287-97. 
25. Song H, Moon HG, Kim SH. Efficacy of quick Sequential Organ Failure Assessment with lactate concentration for predicting mortality in patients with community-acquired pneumonia in the emergency department. Clin Exp Emerg Med. 2019;6(1):1-8.

26. Zhang X, Liu B, Liu Y, Ma L, Zeng H. Efficacy of the quick sequential organ failure assessment for predicting clinical outcomes among communityacquired pneumonia patients presenting in the emergency department. BMC Infect Dis. 2020;20(1):316.

27. Zhou H, Lan T, Guo S. Stratified and prognostic value of admission lactate and severity scores in patients with community-acquired pneumonia in emergency department. Medicine. 2019;98(41):e17479.

28. Asai N, Watanabe $\mathrm{H}$, Shiota $\mathrm{A}$, et al. Efficacy and accuracy of qSOFA and SOFA scores as prognostic tools for community-acquired and healthcareassociated pneumonia. Int J Infect Dis. 2019;84:89-96.

29. Casas-Rojo J, Antón Santos J, Millán Núñez-Cortés J, et al. Características clínicas de los pacientes hospitalizados con COVID-19 en España: resultados del Registro SEMI-COVID-19. Rev Clin Esp. 2020.

30. Ahnert P, Creutz $\mathrm{P}$, Horn $\mathrm{K}$, et al. Sequential organ failure assessment score is an excellent operationalization of disease severity of adult patients with hospitalized community acquired pneumonia - results from the prospective observational PROGRESS study. Crit Care. 2019;23(1):110.

31. Su Y, Tu GW, Ju MJ, et al. Comparison of CRB-65 and quick sepsisrelated organ failure assessment for predicting the need for intensive respiratory or vasopressor support in patients with COVID-19. J Infect. 2020;S01634453(20):30281-4. 
32. Challen K, Bright J, Bentley A, Walter D. Physiological-social score (PMEWS) vs. CURB-65 to triage pandemic influenza: a comparative validation study using community-acquired pneumonia as a proxy. BMC Health Serv Res. 2007;7:33.

33. Ihle-Hansen H, Berge T, Tveita A, et al. COVID-19: Symptoms, course of illness and use of clinical scoring systems for the first 42 patients admitted to a Norwegian local hospital. Tidsskriftet. 2020.

34. Ferreira M, Blin T, Collercandy N, et al. Critically ill SARS-CoV-2-infected patients are not stratified as sepsis by the qSOFA. Ann Intensive Care. 2020;10(1):43.

35. Liu K, Chen Y, Lin R, Han K. Clinical features of COVID-19 in elderly patients: A comparison with young and middle-aged patients. J Infect. 2020;80(6):e14-e8.

36. Fu L, Wang B, Yuan $\mathrm{T}$, et al. Clinical characteristics of coronavirus disease 2019 (COVID-19) in China: A systematic review and meta-analysis. J Infect. 2020;80(6):656-65. 
Figure 1. Flowchart of patients included from the SEMI-COVID-19 Network with COVID-19* pneumonia

${ }^{*}$ COVID-19: coronavirus infectious disease 2019 
Figure 2. Receiver operating characteristic curves for PSI*, CURB65†, MuLBSTA $\ddagger$, and qSOFA§ scores for in-hospital mortality in COVID19\|l pneumonia patients

* PSI: Pneumonia Severity Index; † CURB-65: Confusion, Urea, Respiratory rate, Blood pressure, and age $\geq 65$ years; $\ddagger$ MuLBSTA: Multilobar infiltration, hypo-Lymphocytosis, Bacterial coinfection, Smoking history, hyper-Tension and Age; § qSOFA: quick Sequential Organ Failure Assessment; II COVID-19: coronavirus infectious disease 2019 
Table 1 Epidemiological and clinical characteristics, complications, prognostic scores and outcomes of patients with COVID-19* pneumonia

\begin{tabular}{|c|c|c|c|c|}
\hline & $\begin{array}{l}\text { All patients } \\
\text { n } 10238\end{array}$ & $\begin{array}{l}\text { Non-survivors } \\
\text { n } 2135\end{array}$ & $\begin{array}{l}\text { Survivors } \\
\text { n } 8103\end{array}$ & $p$ \\
\hline \multicolumn{5}{|l|}{ Demographics } \\
\hline Male sex, n (\%) & $5924(57.9)$ & $1336(62.6)$ & $4588(56.6)$ & $<0.001$ \\
\hline Age, mean $\pm S D$, years & $66.6 \pm 16.2$ & $79.5 \pm 10.6$ & $63.2 \pm 15.6$ & $<0.001$ \\
\hline$\geq 70$ years, $\mathrm{n}(\%)$ & 4765 (46.5) & $1810(38)$ & $2955(62)$ & $<0.001$ \\
\hline \multicolumn{5}{|l|}{ Comorbidities, n (\%) } \\
\hline $\begin{array}{l}\text { Moderate or severe } \\
\text { dependency }\end{array}$ & $1504(14.7)$ & 787 (36.9) & $717(8.8)$ & $<0.001$ \\
\hline $\begin{array}{l}\text { Age adjusted Charlson } \\
\text { comorbidity index } \geq 3\end{array}$ & $5830(56.9)$ & $1934(90.6)$ & $3896(48.1)$ & $<0.001$ \\
\hline Hypertension & $5040(49.2)$ & $1496(70.1)$ & $3544(43.7)$ & $<0.001$ \\
\hline Coronary artery disease & $703(6.9)$ & $333(15.6)$ & $370(4.6)$ & $<0.001$ \\
\hline COPD† & $1250(12.2)$ & $502(23.5)$ & $748(9.2)$ & $<0.001$ \\
\hline Cerebrovascular disease & $250(2.4)$ & $116(5.4)$ & $134(1.7)$ & $<0.001$ \\
\hline Smoking history & $2424(23.7)$ & $646(30.3)$ & $1778(21.9)$ & $<0.001$ \\
\hline Active smoking & $492(4.8)$ & $98(4.6)$ & $394(4.9)$ & $<0.001$ \\
\hline Diabetes & $1926(18.8)$ & $618(28.9)$ & $1308(16.1)$ & $<0.001$ \\
\hline Moderate-severe CKD $\ddagger$ & $577(5.6)$ & $261(12.2)$ & $316(3.9)$ & $<0.001$ \\
\hline Malignant tumor & $595(5.8)$ & $199(9.3)$ & $396(4.9)$ & $<0.001$ \\
\hline \multicolumn{5}{|l|}{ Complications, $\mathrm{n}(\%)$} \\
\hline Shock & $482(4.7)$ & $370(17.3)$ & $112(1.4)$ & $<0.001$ \\
\hline Acute Kidney injury & $1423(13.9)$ & $781(36.6)$ & $642(7.9)$ & $<0.001$ \\
\hline Acute Pulmonary Embolism & $158(1.5)$ & $28(1.3)$ & $130(1.6)$ & 0.790 \\
\hline Multi-organic failure & $667(6.5)$ & $375(17.6)$ & $532(6.6)$ & $<0.001$ \\
\hline ARDS§ & $3550(34.7)$ & $1730(81)$ & $1820(22.5)$ & $<0.001$ \\
\hline
\end{tabular}




\begin{tabular}{|c|c|c|c|c|}
\hline Prognostic scores, n (\%) & & & & \\
\hline qSOFAll & 9887 & $2049(20.7)$ & $7838(79.3)$ & .. \\
\hline 0 & $5788(58.6)$ & $552(26.9)$ & $5236(66.8)$ & $<0.001$ \\
\hline 1 & $3219(32.6)$ & $952(46.5)$ & 2267 (28.9) & $<0.001$ \\
\hline 2 & $779(7.8)$ & $464(22.7)$ & $315(4)$ & $<0.001$ \\
\hline 3 & $101(1)$ & $81(3.9)$ & $20(0.3)$ & $<0.001$ \\
\hline CURB-65ף & 9887 & $2049(20.7)$ & $7838(79.3)$ & .. \\
\hline $0-1$ & $5899(59.7)$ & $366(17.9)$ & $5533(70.6)$ & $<0.001$ \\
\hline 2 & $2232(22.6)$ & $657(32.1)$ & $1575(20.1)$ & $<0.001$ \\
\hline 3 & $1282(12.9)$ & $679(33.1)$ & $603(7.7)$ & $<0.001$ \\
\hline 4 & $438(4.4)$ & $317(15.5)$ & $121(1.5)$ & $<0.001$ \\
\hline 5 & $36(0.4)$ & $30(1.4)$ & $6(0.1)$ & $<0.001$ \\
\hline PSI\# & 9261 & $1906(20.6)$ & $7355(79.4)$ & .. \\
\hline I-II & $3376(36.5)$ & $55(2.9)$ & $3321(45.2)$ & $<0.001$ \\
\hline III & $2168(23.4)$ & 247 (12.9) & $1921(26.1)$ & $<0.001$ \\
\hline IV & $2566(27.7)$ & $860(45.1)$ & $1706(23.2)$ & $<0.001$ \\
\hline V & $1151(12.4)$ & 744 (39.1) & 407 (5.5) & $<0.001$ \\
\hline MuLBSTA $^{\star *}$ & 9505 & $1956(20.6)$ & $7549(79.4)$ & .. \\
\hline MuLBSTA $\geq 12$ & $1298(13.7)$ & $588(30.1)$ & $710(9.4)$ & $<0.001$ \\
\hline Outcomes, n (\%) & & & & \\
\hline NIV†† & $528(5.2)$ & $269(12.6)$ & 259 (3.2) & $<0.001$ \\
\hline Mechanical ventilation & $722(7.1)$ & $340(15.9)$ & $382(4.7)$ & $<0.001$ \\
\hline Admission to ICU $\ddagger \ddagger$ & 907 (8.9) & $375(17.6)$ & $532(6.6)$ & $<0.001$ \\
\hline Mortality & $2135(20.9)$ & -- & -- & -- \\
\hline $\begin{array}{l}\text { Length of hospital stay, } \\
\text { mean } \pm S D \text {, days }\end{array}$ & $11.2 \pm 9.2$ & $9.7 \pm 10.3$ & $11.6 \pm 8.8$ & $<0.001$ \\
\hline
\end{tabular}

* COVID-19: coronavirus infectious disease 2019; † COPD: chronic obstructive pulmonary disease; $\ddagger C K D$ : chronic kidney disease; $\S$ ARDS: acute respiratory distress syndrome; II qSOFA: quick Sequential Organ Failure Assessment; ף CURB- 
65: Confusion, Urea, Respiratory rate, Blood pressure, and age $\geq 65$ years; \# PSI: Pneumonia Severity Index; ${ }^{* *}$ MuLBSTA: Multilobar infiltration, hypo-Lymphocytosis, Bacterial coinfection, Smoking history, hyper-Tension and Age; †† NIV: non-invasive ventilation; łł. ICU: intensive care unit. 
Table 2. Statistical data of ROC* curve comparisons between PSI†, CURB-65‡, MuLBSTA§ and qSOFAll scores for in-hospital mortality in patients with COVID19ף pneumonia

\begin{tabular}{|l|l|l|l|l|}
\hline & AUROC\# $(95 \% \mathrm{Cl})$ & vs. PSI† & vs. CURB-65 $\ddagger$ & vs. MuLBSTA§ \\
\hline PSI† & $0.835(0.826-0.845)$ & -- & -- & -- \\
\hline CURB-65 $\ddagger$ & $0.825(0.815-0.835)$ & 0.112 & -- & -- \\
\hline MuLBSTA§ & $0.715(0.703-0.727)$ & $<0.001$ & $<0.001$ & -- \\
\hline qSOFAll & $0.728(0.715-0.741)$ & $<0.001$ & $<0.001$ & 0.102 \\
\hline
\end{tabular}

* ROC: receiver operating characteristic curve; † PSI: Pneumonia Severity Index; ¥ CURB-65: Confusion, Urea, Respiratory rate, Blood pressure, and age $\geq 65$ years; § MuLBSTA: Multilobar infiltration, hypo-Lymphocytosis, Bacterial coinfection, Smoking history, hyper-Tension and Age; II qSOFA: quick Sequential Organ Failure Assessment; I COVID-19: coronavirus infectious disease 2019; \# AUROC: area under the receiver operating characteristic curve. 
Table 3 Comparison of predictive assessments between PSI ${ }^{*}$, CURB-65†, MuLBSTA $\ddagger$ and qSOFA§ scores for in-hospital mortality in patients with COVID-19II pneumonia

\begin{tabular}{|l|l|l|l|l|}
\hline & Sensitivity, \% (95\% Cl) & Specificity, \% (95\% CI) & PPV I, \% (95\% CI) & NPV\#, \% (95\% CI) \\
\hline PSI $\geq I V$ & $84.12(82.45-85.79)$ & $72.25(71.21-73.29)$ & $44.28(42.65-45.91)$ & $94.55(93.94-95.15)$ \\
\hline CURB-65 $\geq 3$ & $82.13(80.45-83.82)$ & $70.59(69.57-71.60)$ & $42.20(40.65-43.74)$ & $93.79(93.17-94.41)$ \\
\hline MuLBSTA $\geq 12$ & $27.54(25.62-29.45)$ & $91.23(90.61-91.85)$ & $45.30(42.55-48.04)$ & $82.69(81.90-83.48)$ \\
\hline qSOFA $\geq 2$ & $26.59(24.66-28.53)$ & $95.72(95.27-96.18)$ & $61.93(58.66-65.19)$ & $83.30(82.52-84.07)$ \\
\hline
\end{tabular}

* PSI: Pneumonia Severity Index; † CURB-65: Confusion, Urea, Respiratory rate, Blood pressure, and age $\geq 65$ years; $\ddagger$ MuLBSTA: Multilobar infiltration, hypo-Lymphocytosis, Bacterial coinfection, Smoking history, hyper-Tension and Age; $\S$ qSOFA: quick Sequential Organ Failure Assessment; II COVID-19: coronavirus infectious disease 2019; I PPV: positive predictive value; \# NPV: negative predictive value. 
Figure 1

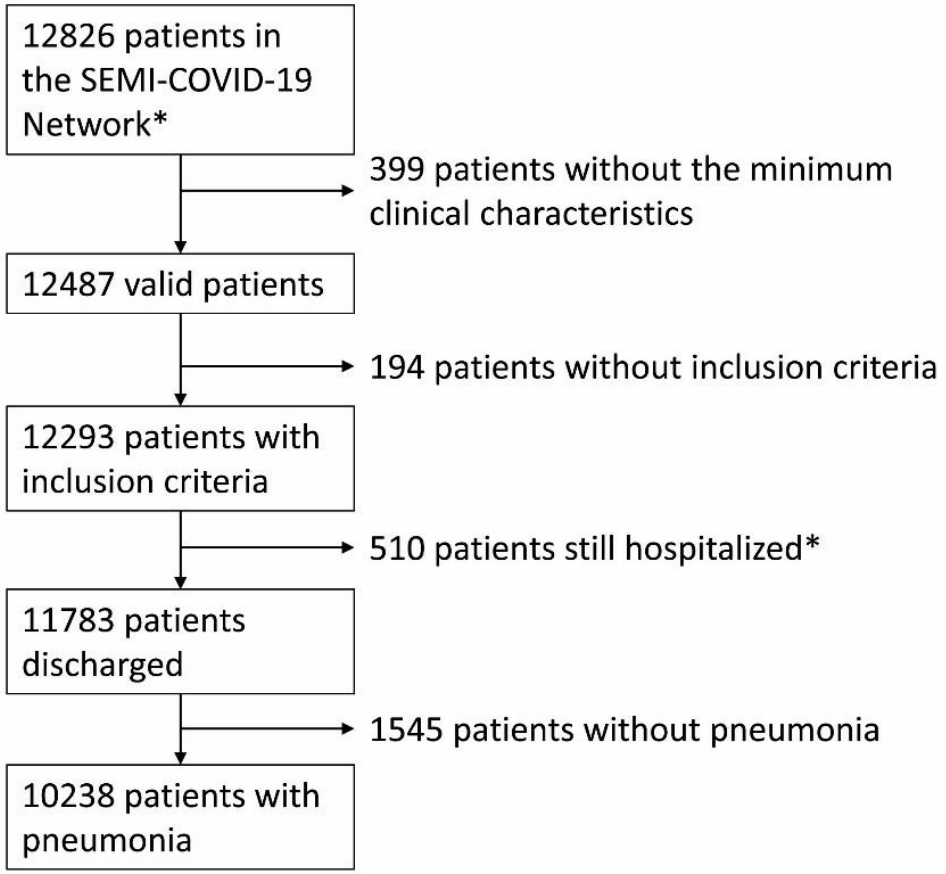

* At 29th may 2020 
Figure 2

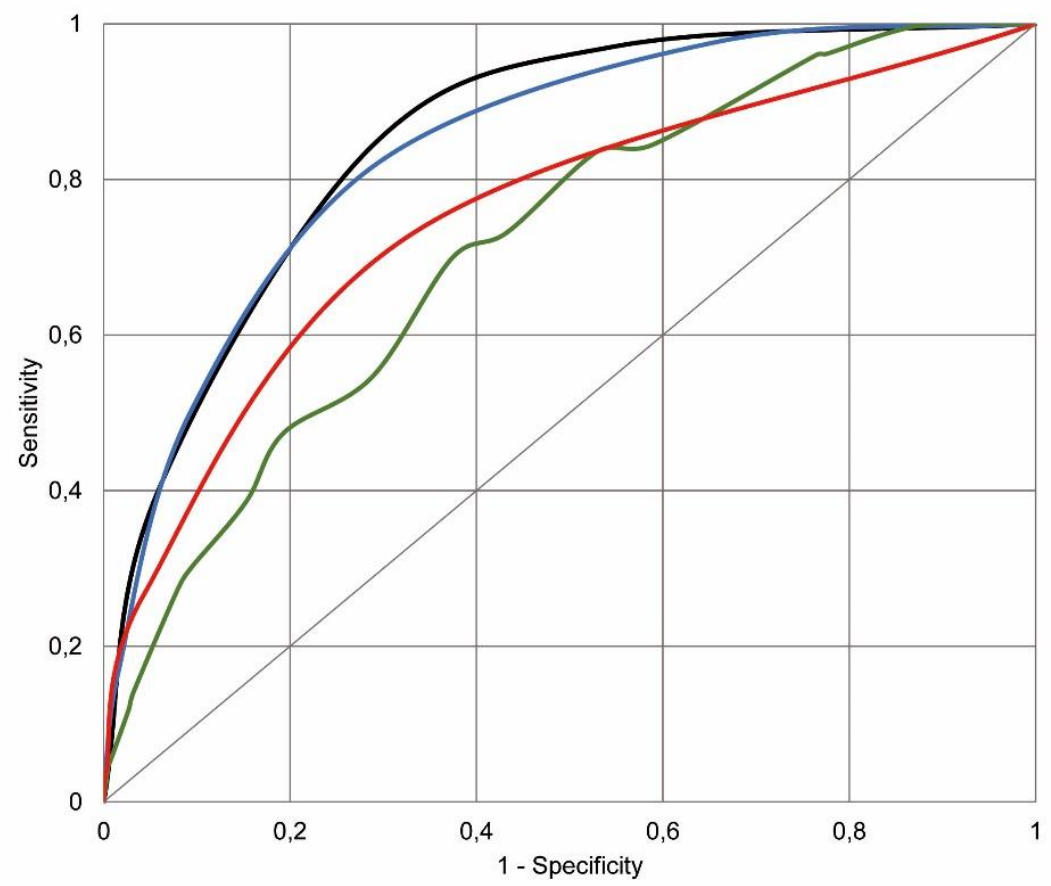

—PSI - CURB65 -MuLBSTA -qSOFA 
Figures

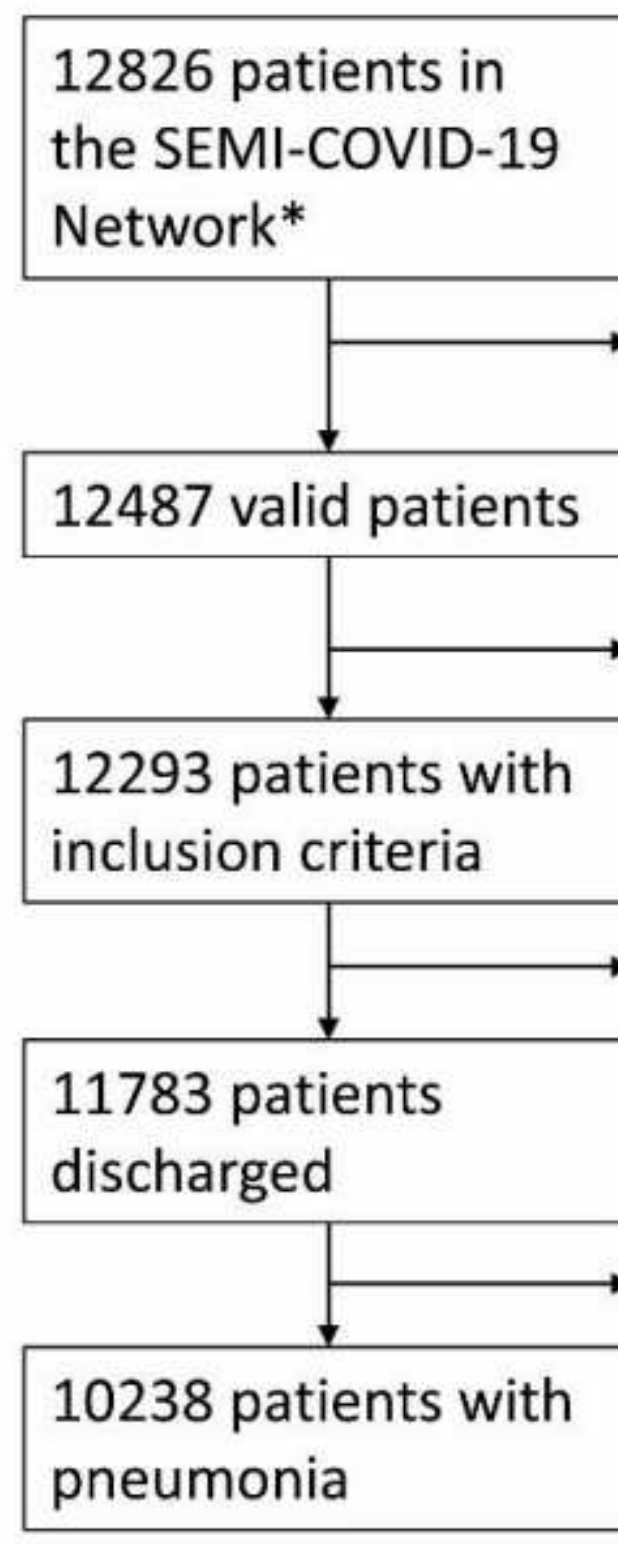

399 patients without the minimum clinical characteristics

194 patients without inclusion criteria

510 patients still hospitalized*

- 1545 patients without pneumonia

10238 patients with pneumonia

* At 29th may 2020

Figure 1

Flowchart of patients included from the SEMI-COVID-19 Network with COVID-19* pneumonia *COVID-19: coronavirus infectious disease 2019 


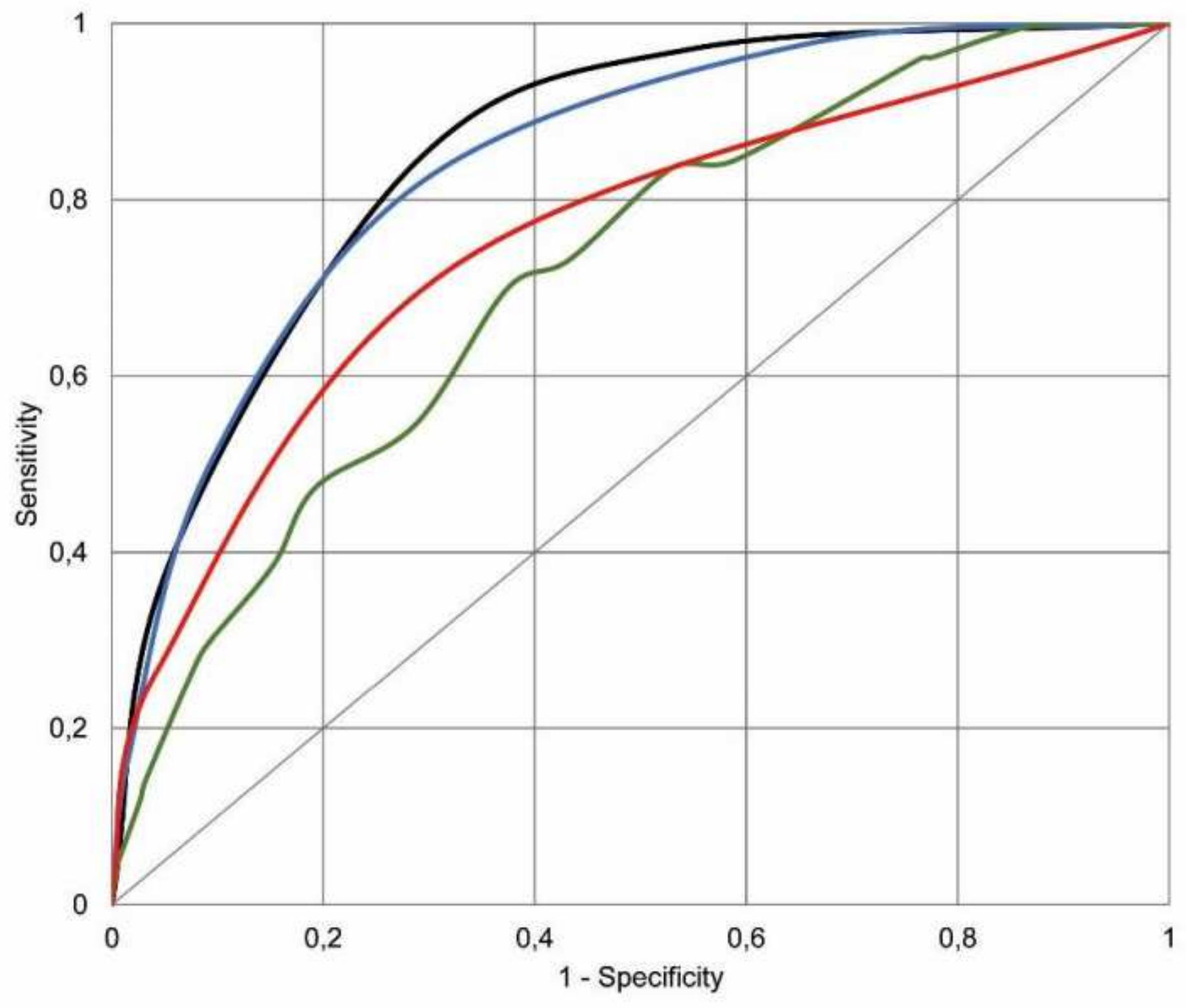

-PSI -CURB65 -MULBSTA -qSOFA

Figure 2

Receiver operating characteristic curves for PSI*, CURB65t, MuLBSTA hospital mortality in COVID19ه pneumonia patients * PSI: Pneumonia Severity Index; † CURB-65: Confusion, Urea, Respiratory rate, Blood pressure, and age $\geq 65$ years; $¥$ MuLBSTA: Multilobar infiltration, hypo-Lymphocytosis, Bacterial coinfection, Smoking history, hyper-Tension and Age; § qSOFA: quick Sequential Organ Failure Assessment; $\Downarrow$ COVID-19: coronavirus infectious disease 2019 